\title{
Recurrent urinary tract infection as presenting feature of genito-urinary tuberculosis: reports of two cases
}

\author{
Rahim MA ${ }^{\mathrm{a}}$, Hossain $\mathrm{M}^{\mathrm{b}}$, Zaman $\mathrm{S}^{\mathrm{c}}$, Uddin $\mathrm{KN}^{\mathrm{d}}$
}

\begin{abstract}
Genito-urinary tract is one of the most common extra-pulmonary sites of involvement by tuberculosis. Genitourinary tuberculosis poses significant diagnostic difficulty; not only because of non-specific symptoms, but also because of lack of diagnostic facility, specially, in resource constrain settings. We report two cases of genito-urinary tuberculosis occurring among Bangladeshi adult females, who presented with recurrent urinary tract infection. Along with other supportive tests, acid fast bacilli were identified on urine examinations.
\end{abstract}

Key words: genito-urinary tract, Mycobacterium tuberculosis, tuberculosis, urinary tract infection.

(BIRDEM Med J 2020; 10(3): 212-214)

\section{Introduction}

Tuberculosis is common, can involve various organs and systems of the body and may have different presentations. ${ }^{1}$ Genito-urinary tuberculosis constitutes the second most common form of extra-pulmonary tuberculosis. ${ }^{2}$ Patients may present with fever, anorexia, weight loss, sterile pyuria, recurrent urinary tract infection (UTI), hydro-ureteronephrosis and renal failure. ${ }^{2,3}$ Identification of acid fast bacilli (AFB) in urine microscopy and cultures or a positive Mycobacterium tuberculosis-polymerase chain reaction (MTB-PCR) from urine samples remain important tools in diagnosing genito-urinary tuberculosis. ${ }^{3}$ Here, we report two cases of genito-urinary tuberculosis who presented with recurrent UTI.

\section{Case reports}

Case 1

A 55-year-old lady, diagnosed case of diabetes mellitus and on oral anti-diabetic medications, presented with a 2week history of intermittent fever, with occasional evening

Author information

a. Muhammad Abdur Rahim, Associate Professor, Nephrology, BIRDEM General Hospital, Dhaka, Bangladesh.

b. Mostaque Hossain, Assistant Professor, Medicine, Shaheed Taj Uddin Ahmad Medical College, Gazipur, Bangladesh.

c. Shahana Zaman, Assistant Professor, Cardiology, NICVD, Dhaka, Bangladesh.

d. Khwaja Nazim Uddin, Professor, Internal Medicine, BIRDEM General Hospital, Dhaka, Bangladesh.

Address of correspondence: Muhammad Abdur Rahim, Associate Professor, Nephrology, BIRDEM General Hospital, Dhaka, Bangladesh. Email: muradrahim23@yahoo.com

Received: June 22, 2020

Accepted: June 30, 2020 rise of temperature and dysuria. She received treatment for UTI twice in last 3 months. On admission, she was afebrile with normal hemodynamic status. There was mild suprapubic tenderness. Other examination findings were unremarkable. Bed side urine revealed proteinuria $(+)$.

The lady had poor control of diabetes, neutrophil leukocytosis and high erythrocyte sedimentation rate (ESR) (Table I). Tuberculin test revealed $13 \mathrm{~mm}$ induration at 72 hours. Ultrasonogram showed swollen left kidney. Urine routine examination showed pyuria and culture did not grow any organism. Morning samples of urine were positive for AFB in two consecutive samples. Serum creatinine was raised (Table I). She was started with antituberculosis drugs (modified doses for ethambutol and pyrazinamide) along with pyridoxine. Her blood glucose was controlled with split-mixed regimen of insulin.

\section{Case 2}

An 80-year-old diabetic lady presented with fever for 4 months along with anorexia, weight loss of $6 \mathrm{~kg}$ and urinary incontinence. She was mildly aneamic and afebrile during admission. She had non-proliferative diabetic retinopathy.

She had anaemia, poor glycaemic status and microscopic haematuria (Table I). Urine and blood cultures appeared sterile. She had a normal chest radiograph and tuberculin test was $8 \mathrm{~mm}$ at 72 hours. Ultrasonogram showed features of early renal parenchymal disease, mild obstructive features with suspected right nephrolithiasis. Urine AFB on $3^{\text {rd }}$ sample became positive and urine for MTB-PCR was also positive. Anti-tuberculosis medication was started along with pyridoxine and other medications were continued. 
Table I Demographic, clinical and laboratory features of patients with genito-urinary tuberculosos

\begin{tabular}{|c|c|c|}
\hline Parameters & Case 1 & Case 2 \\
\hline$\overline{\text { Age (years) }}$ & 55 & 80 \\
\hline Duration of diabetes (years) & 6 & 20 \\
\hline Past history of UTI & $\begin{array}{l}\text { Yes, twice in } 3 \text { month, } \\
\text { E. coli in both instances }\end{array}$ & $\begin{array}{l}\text { Yes, four times in one } \\
\text { year }\end{array}$ \\
\hline RBS at admission (m.mol/L) & 16.7 & 10.2 \\
\hline $\mathrm{HbA1c}(\%)$ & 8.1 & 8.6 \\
\hline $\mathrm{Hb}(\mathrm{gm} / \mathrm{dl})$ & 9.7 & 9.5 \\
\hline TC of WBC/cmm blood & $17500(\mathrm{~N}-94 \%)$ & $7400(\mathrm{~N}-63 \%)$ \\
\hline $\mathrm{ESR}\left(\mathrm{mm}\right.$ in $1^{\text {st }}$ hour $)$ & 78 & 130 \\
\hline \multicolumn{3}{|l|}{ Urine RE } \\
\hline Pus cell & Plenty/HPF & 12-14/HPF \\
\hline Red blood cell & 2-4/HPF & Plenty/HPF \\
\hline Epithelial cell & $0-2 / \mathrm{HPF}$ & 4-6/HPF \\
\hline Protein & ++ & ++ \\
\hline Glucose & + & Nil \\
\hline Acetone & Nil & Nil \\
\hline Urine culture & No growth & No growth \\
\hline Blood culture & No growth & No growth \\
\hline Chest x-ray & Normal & Normal \\
\hline USG & Swollen upper pole of left kidney & $\begin{array}{l}\text { Early renal parenchymal } \\
\text { disease, mild obstructive feature } \\
\text { in left side }\end{array}$ \\
\hline MT & $13 \mathrm{~mm}$ induration at 72 hours & $8 \mathrm{~mm}$ induration at 72 hours \\
\hline \multirow[t]{3}{*}{ Urine AFB } & Present in $1^{\text {st }}$ sample & AFB not found \\
\hline & Present in $2^{\text {nd }}$ sample & AFB not found \\
\hline & - & Present in $3^{\text {rd }}$ sample \\
\hline Urine MTB-PCR & - & Positive \\
\hline Serum creatinine & $2.2 \mathrm{mg} / \mathrm{dl}$ & $1.3 \mathrm{mg} / \mathrm{dl}$ \\
\hline \multicolumn{3}{|l|}{ Serum electrolytes } \\
\hline $\mathrm{Na}-\mathrm{K}-\mathrm{Cl}-\mathrm{HCO}_{3}$ & $127-5.5-97-21$ & $139-3.7-97-31$ \\
\hline
\end{tabular}

$[\mathrm{UTI}=$ urinary tract infection, $\mathrm{RBS}=$ random blood glucose, $\mathrm{HbA1c}=$ glycated haemoglobin, $\mathrm{Hb}=$ haemoglobin, $\mathrm{TC}=$ total count, $\mathrm{WBC}=$ white blood cells, $\mathrm{ESR}=$ erythrocyte sedimentation rate, $\mathrm{RE}=$ routine examination, $\mathrm{USG}=$ ultrasonogram, $\mathrm{MT}$ $=$ Mantoux test, $\mathrm{AFB}=$ acid fast bacilli, MTB-PCR = Mycobacterium tuberculosis-polymerase chain reaction]

\section{Discussion}

Tuberculosis is an ancient disease and remains as a major global public health issue. Tuberculosis can involve every organs of the body; extra-pulmonary disease constitutes one-fourth of cases $^{2}$ and genitourinary tuberculosis is one of the most common extrapulmonary sites infected by M. tuberculosis and it is secondary to tuberculosis elsewhere. Patients with pulmonary tuberculosis have a 2-20\% risk of developing genito-urinary tuberculosis after a lag of 20 years. ${ }^{2-4}$ Risk factors include diabetes mellitus, increasing age, chemotherapy, post-transplant status and cancer chemotherapy etc. Most patients have non-specific symptoms and patients may present late with obstructive features and renal failure. ${ }^{2,5}$

Diagnosis is often delayed due to non-specific symptoms and failure to suspect early in disease course. Urine for AFB and MTB-PCR are sufficient for establishing the 
diagnosis but these tests are not widely available, specially, in resource constrain conditions. A chest xray may show concomitant active pulmonary lesion or healed ones. ${ }^{3,6}$ High ESR and positive tuberculin tests are important in making a diagnosis. ${ }^{3}$ A plain abdominal $\mathrm{x}$-ray may show calcification the regions of kidneys. Image guided fine needle aspiration cytology (FNAC) and biopsy are of use in selected cases. ${ }^{7}$

Treatment consists of standard anti-tuberculosis medications. Steroids may be indicated to reduce chance of ureteric strictures and sometimes surgery may be needed. ${ }^{2,7}$

Our patients were diabetic, elderly and had recurrent urinary tract infections. They had high ESR, AFB in urine, positive MTB-PCR in the second case and significant induration in Mantoux test (MT) in first case. All these helped in establishing the diagnosis.

In conclusion, it can be said that patients with recurrent UTI should be investigated thoroughly for underlying cause and genito-urinary tuberculosis should be suspected in appropriate scenario, specially, if risk factors are present.

Conflict of interest: Nothing to declare.

\section{References}

1. Haque WMMU, Shuvo MER, Rahim MA, Mitra P, Samad T, Haque JA. Haemophagocytic syndrome in an adult suffering from pyrexia of unknown origin: an uncommon presentation of tuberculosis: a case report. BMC Res Notes 2017;10:110.

2. Figueiredo AA, Lucon AM, Srougi M. Urogenital Tuberculosis. Microbiol Spectr 2017 Jan;5(1). doi: 10.1128/ microbiolspec. TNMI7-0015-2016.

3. Singh JP, Priyadarshi V, Kundu AK, Vijay MK, Bera MK, Pal DK. Genito-urinary Tuberculosis revisited - 13 Years' Experience of a Single Centre. Indian J Tuberc 2013 Jan;60(1):15-22.

4. Tanthanuch M, Karnjanawanichkul W, Pripatnanont C. Tuberculosis of the urinary tract in southern Thailand. J Med Assoc Thai 2010 Aug;93(8):916-19.

5. Christensen WI. Genitourinary Tuberculosis: Review of 102 Cases. Medicine (Baltimore) 1974 Sep;53(5):377-90.

6. Orakwe JC, Okafor PI. Genitourinary tuberculosis in Nigeria; a review of thirty-one cases. Niger J Clin Pract 2005 Dec; 8(2):69-73.

7. Dje K, Yao B, D'Horpock FA, Tchimou J. Urogenital tuberculosis: diagnostic difficulties in 5 cases. Ann Urol (Paris) 2003 Oct;37(5):233-35. 